\title{
REFLECTIONS ON THE CONCEPT AND CONCEPTU- ALISATION OF THE URBAN NEIGHBOURHOOD IN SOCIETIES IN TRANSITION: THE CASE OF PRETORIA (SOUTH AFRICA)
}

\author{
André Horn \\ Department of Geography, Geoinformatics and Meteorology \\ University of Pretoria, Pretoria, 000I, South Africa \\ e-mail: ahorn@postino.up.ac.za
}

\begin{abstract}
In the article socio-economic analysis of neighborhood is presented on the basis of big ethnically defined neighborhoods in Pretoria and the practice of the inhabitants thereof: communications, activities, relation to environment, activities of individuals, form of neighborhoods. A neighborhood is defined as a form of interaction of natural and social environment.
\end{abstract}

Key words: Pretoria, neighborhood, socio-economic structure, ethnical groups, socio-olitical changes.

\section{THE URBAN NEIGHBOURHOOD: CONCEPT AND CONTEXT Introduction}

Sense of neighbourhood is one of the qualities that define urbanity as a settlement construct and urbanism as a way of life. Because of varying opinions on the importance of neighbourhood under different spatial and temporal conditions the study of sense of neighbourhood continuous to be relevant. The proclaimed value of this paper is in the adopted multi-faceted structure of sense of neighbourhood, the distributed cluster sampling technique used, the focus on an urban society amidst rapid socio-political transition, and the perspective on a relatively young urban tradition in the developing South.

The concept of urban neighbourhood is closely linked to the understanding of community and localism (Durkheim, 1933; Zimmerman, 1938; Tönnies, 1963). However, the neighbourhood concept is elusive and its definition is influenced by type, lifestyle and contextualities (Muller, 1981; Fischer, 1984; Parkes et al., 2002). In early-modern societies the neighbourhood was defined by common physical dependences, the need for mutual support and control over behaviour, and very often by religious institutions (Garrioch, 2001). 
In modern society the neighbourhood became a mechanism in relation to immigration, territorial control, and urbanisation processes giving rise to the contextuality theory (Park et al., 1925; Wirth, 1938). Under these conditions the block, local school and the church became the cornerstones of community life (Keller, 1968; Suarez, 2000; Moeser, 2001). To the present the influence of the locale on various aspects of urban life is widely acknowledged (Wilson 1987; Geis and Ross, 1998; Rankin and Quane 2000; Ainsworth, 2002; Gibbons, 2003). But the destructive effect on the neighbourhood of the rise of mass society, modernisation, increased socio-spatial mobility, improved interconnectivity, and social inclusion policies cannot be denied (Webber, 1963; Kasarda and Janowitz, 1974; Porteous, 1977; Fischer, 1982, 1984; Moeser, 2001). In many circles the importance of the neighbourhood has been questioned for some time (Gans, 1962; Michelson, 1970; Lyon, 1989; South and Crowder, 2000; Sies, 2001; Ostendorf et al., 2002; Uitermark, 2003). For some, present day neighbourhoods are reminders of community without the reality of community (Suarez, 2000). Yet, the debate on the importance of the neighbourhood to urban living is particularly relevant at this point in time. Juxtaposed with the 'community lost' tendency of the modernist era, late-modernism is associated with a number of 'community saving and forming' drives (Herbert and Thomas, 1982; Ellen and Turner, 1997). Such pro-neighbourhood forces include the strategy of new urbanism and the design ideology of new urbanism (Calthorpe, 1993); neighbourhood renewal strategies in various parts of the world (Parkes et al., 2002); the multiple partitioning of shared space in late-modernist societies (Schnell et al., 2002); public participation in local area planning and management processes (Walker, 1989); area sensitive socio-economic inclusion and empowerment strategies (Kallus and Law-Yone, 2000); and growing recognition of the role of local-based social and cultural capital (Briggs, 2001).

Influenced by the awakening of neo-traditionalism as paradigm for urban living, 'sense of neighbourhood' has become the core concept through which neighbourhood attachment and communality is being evaluated (Talen, 1999). In an attempt to extend the growing volume of literature on the relative importance of the neighbourhood in stable, developed countries, the focus has now also shifted to societies in transition (e.g. Schnell et al., 2002). To this extent the present paper adds the dimension of society in transition in the developing South through attention on sense of neighbourhood in the greater Pretoria region. In the past, neighbourhood-based local communities were the foundations of South African urban societies. This was brought about, first, by apartheid policies fragmenting society into structural and spatial racial categories. In addition, white society was strictly organised on a territorial basis in which the local school and church played central roles. Black society, confined to the hardship of poorly developed residential townships survived on the basis of a long-established African tradition of ubuntu, a form of propinquity and communality that originated in traditional African rural society. The end of apartheid resulted in a comprehensive program of overall transformation driven by a new democratically elected, centralist government. Although the principle of community driven problemsolving, decision-making and development implementation, similar to the neo-localism drive in the developed world, is a cornerstone of the mindset of the new regime, the reality of spatial integration, social inclusion, race and class desegregation and political transfor- 
mation policies is in stark contrast with the new urbanism strategy as it is understood globally. Moreover, indications are that the South African society is at present traumatised and confused as a result of too many radical changes and that communities across the board are degenerated (Prinsloo, 1998). Hence, the study of sense of neighbourhood in the South African city at this point in time is related to the alternative arguments of 'community lost', 'community saved' and 'community transformed' as proposed by Wellman (1979), mainly to investigate the importance and manifestations of the neighbourhood in a developing city of the South amidst rapid socio-political transition.

Various frameworks for the study of sense of neighbourhood have been introduced (May, 1983; Fischer, 1984; McMillan and Chavis, 1986; Parkes et al., 2002; Woldoff, 2002). These frameworks largely overlap. The main differences are the emphasis that is placed on different facets of sense of neighbourhood, and the inclusion or exclusion of sense of place in the analysis. This study was based on a multi-faceted concept of sense of neighbourhood incorporating the aspects of attitude (sentiment and evaluation), community (relations and consensus), and territoriality (spatio-temporal operations and neighbourhood delineation).

Data collection took the form of structured, personal interviews in twenty-two welldistributed clusters in greater Pretoria). This municipality, with about 1.8 million inhabitants that was formed through the amalgamation of more than thirteen previously autonomous, local authorities into a centrally managed mega-city based on a nationally prescribed model of urban integration and redevelopment (South Africa, 1995; 1998). The sample included $n=154$ respondents proportionately representing the population and including a range of professions (Table 1). The median age of respondents were 33.8 years and the average period of residence in Pretoria was 17.5 years.

Table 1: Sample

\begin{tabular}{|l|rl|}
\hline Race & \multicolumn{2}{|c|}{ Profession } \\
\hline \multirow{2}{*}{77 African } & 43 & White collar professionals \\
& 34 & Other skilled workers \\
\hline \multirow{2}{*}{56 White } & 27 & Labourers \\
& 24 & Student and part-time workers \\
\hline \multirow{2}{*}{11 Indian } & 16 & Mothers and homemakers \\
& 5 & Unemployed \\
\hline \multirow{2}{*}{10 Coloured } & 4 & Pensioners \\
& 1 & Sex worker \\
\hline \multirow{2}{*}{$\mathrm{n}=154$} & & $\mathrm{n}=154$ \\
\hline
\end{tabular}

At present a variety of approaches, from positivist to post-modern is being used to study sense of place. Because of the absence of consensus on the characteristics of neighbourhoods and because of the flexible, often unrelated facets of sense of neighbourhood a typological, descriptive approach focussing on the importance and manifestations of the neighbourhood concept - assuming the relevance of neighbourhoods to urban living as given - rather than a positivist, hypothesis-based approach was followed. 


\section{FINDINGS}

The main findings are discussed in sections representing the main aspects of sense of place as displayed in the conceptual framework, above.

\section{Attitude}

Attitudes toward the neighbourhood are generally analysed through the variables sentiment and evaluation (Woldoff, 2002)

Sentiment: Considering sentiment towards the neighbourhood, it should be taken into account that many people do not live in the neighbourhood of their choice and that few neighbourhoods are anything more than temporary platforms for upward and outward mobility of their residents (Goering, 1978). Therefore, sentiment is not so much about territorial behaviour as it is about the association between meanings attached to physical space and a person's self-image (Hull, 1992).

In Pretoria, $97.0 \%$ of respondents could link their local area with a place name - name being a key component of sense of place (Relph, 1976). Majority consensus about the name of respective local areas amounted to $79.0 \%$. Although $79.8 \%$ of respondents viewed their locale as a neighbourhood, only $26.6 \%$ considered the neighbourhood per se as important to their lives. Compared to a recent study in Tel-Aviv - Jaffa (Schnell et al., 2002) the Pretoria case study showed a $10 \%$ higher appreciation of local areas as neighbourhoods while $10 \%$ fewer Pretorians considered their neighbourhoods as important. These findings may point to persistent neighbourhood sentiments that are not supported by neigh-bourhood realities.

Given that neighbourhood perception attributes more to understanding neighbourhood satisfaction than anything else (Parkes et al., 2002) each respondent was asked to identify up to three local area symbols. Figure 1 shows that positive 'social' and 'environmental qualities' are predominant social area symbols, but that social disorder is also an important neighbourhood characteristic. The nature and location attributes of social disorder, amongst other variables, are discussed in the next section.

Figure 1: Local area symbols

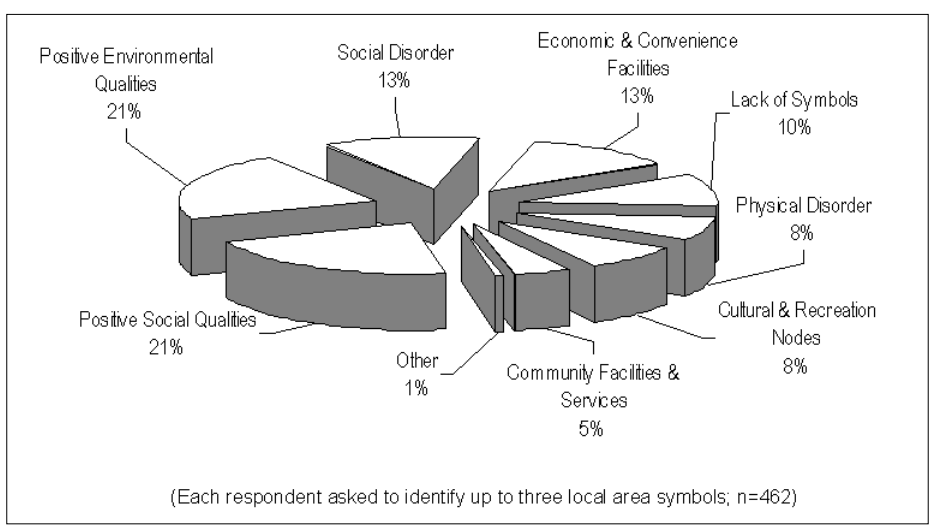


Evaluation: Evaluation is a means of expressing the quality of neighbourhood life. Parkes et al. (2002) uses 'satisfaction' while Woldoff (2002) places particular emphasis on social and physical 'order' and 'disorder' as indicators of the quality of local experiences.

Throughout the city of Pretoria a total of $72.7 \%$ of respondents were clearly proud of their local areas while $38.0 \%$ indicated the desire to move out of their present neighbourhoods. The correlation between the variables 'not proud' and 'desire to move' was weak $\left(\mathrm{r}^{2}=0.39\right)$ suggesting that the desire to relocate is motivated by more than just negative sentiments about the neighbourhood. In fact, only $42.3 \%$ of respondents linked their 'desire to move' to local area 'push factors' while the same percentage, $42.3 \%$, linked their desire to move to 'pull factors' in other areas. A further $11.9 \%$ was motivated by 'lifecycle dynamics' and $3.5 \%$ provided no specific reason for wanting to relocate.

Next, respondents were asked to identify up to three each of positive and negative neighbourhood characteristics. Figure 2 indicates that responses that can be summarised as 'environmental qualities', local 'facilities' and 'population and community' account for almost $60 \%$ of positive neighbourhood characteristics. The relative under-valuation of 'social order' as a positive neighbourhood characteristic in Pretoria is also noticeable. However, Figure 3 shows that, since the end of apartheid, after 10 years of transformation, 'social disorder' is the most important negative neighbourhood characteristic in Pretoria, accounting for one-third of negative neighbourhood characteristics. Following global trends (see Parkes et al., 2002) 'crime and insecurity' is also the most significant source of social disorder in neighbourhoods in Pretoria and affects all areas similarly, followed by 'loitering and hawking'. Although the impact of 'street prostitution' as a source of social disorder is not as big in the city at large, it is a particular problem in inner-city areas. 'Physical disorder' is a second major negative neighbourhood characteristic and includes problems related to 'traffic' in all areas, 'noise' levels in the inner-city, and 'land-use' transgressions in the suburbs. 'Lack of facilities' is also perceived as a negative neighbourhood characteristic in both the black townships as well as the less affluent white neighbourhoods, but is considered, even in these areas, as less of a problem than crime and insecurity.

Figure 2: Positive neighbourhood characteristics

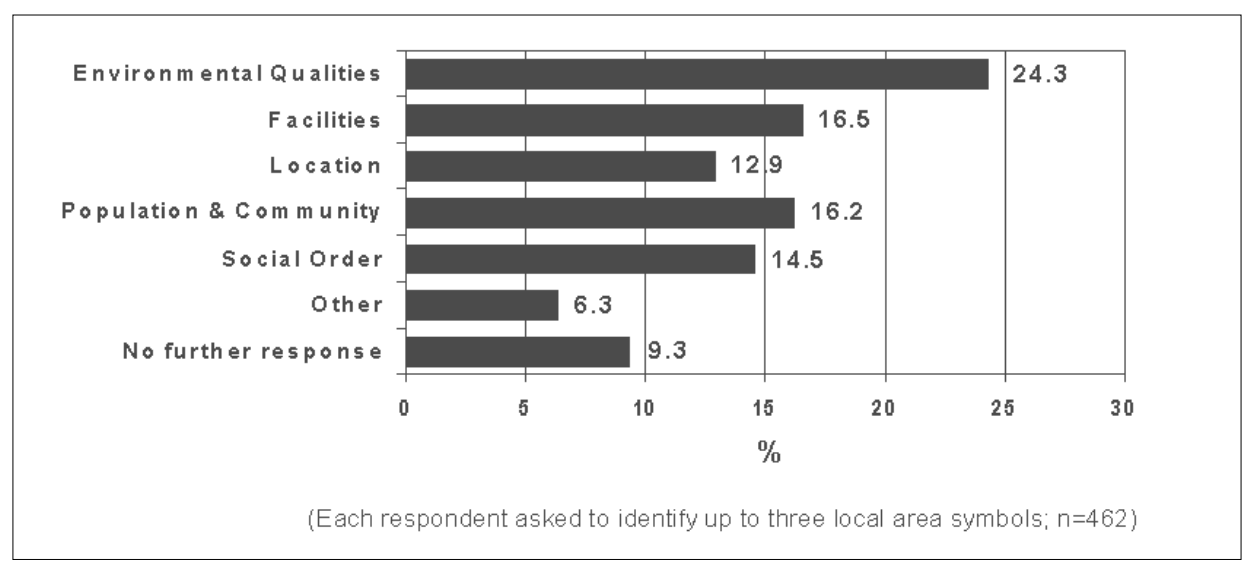


Figure 3: Negative neighbourhood characteristics

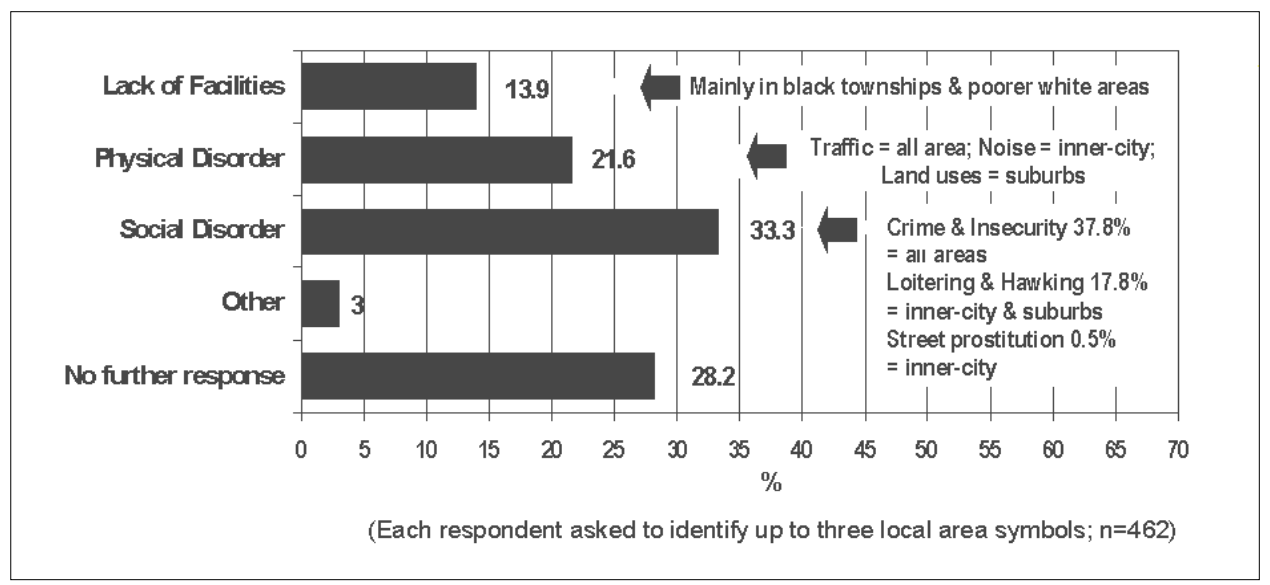

Worldwide, perceived 'order' and 'disorder' are the primary determinants of neighbourhood satisfaction with 'crime' a major threat to neighbourhood sanctimony (Geis and Ross, 1998; Parkes et al., 2002). However, the lack of social order as a positive influence and the high incidence of social disorder as a negative influence have become major characteristics of postapartheid South African neighbourhoods.

\section{Community}

A large portion of urban residents define neighbourhood in terms of networks of associations and shared sense of community (Wellman and Leighton, 1979).

Relations: Shared connections are probably the most important indicators of neighbourhood community. Variables of neighbourhood relations include 'identification' of individuals, 'frequency of communication', and the 'nature of relationships'. In Pretoria $84.5 \%$ of respondents knew at least one of their neighbours by name. In addition $85.1 \%$ knew somebody other than the nearest neighbours by name and only $3.2 \%$ did not know anybody in the neighbourhood by name.

Two thirds of neighbours communicate with each other at least once per week but almost the same percentage indicated that neighbourly relations were friendly but not social (Table 2). There were also no significant correlations between, frequency of communication or nature of relationships on the one hand, and location in the city or race on the other hand. A further variable of neighbourhood commitment is personal neighbourhood related activities as freely indicated by respondents. On a relative scale Table 3 suggests that local area activities are comprehensive and varying from sport and recreation, and religious activities to shopping as well as social and community activities despite respondents' low rating of the importance of the neighbourhood in their lives. On the whole, contemporary South African urban neighbourhood provides a number of functions other than shopping facilities. 
Table 2: Frequency of communication and nature of relationships

\begin{tabular}{|l|l|c|}
\hline Frequency of communication & At least once per week & Seldom or by necessity \\
\hline Every day & $38.3 \%$ & $32.5 \%$ \\
\hline $29.2 \%$ & \multicolumn{2}{|c|}{$\mathrm{r}^{2}$ (communication $\mathrm{x}$ race) $=0.11$} \\
\hline $\mathrm{r}^{2}$ (communication x location) $=0.07$ & Impersonal \\
\hline Nature of relationships & Friendly but not social & $4.5 \%$ \\
\hline Personal and social & $66.3 \%$ \\
\hline $29.2 \%$ & $\mathrm{r}^{2}$ (relationship x race) $=0.37$ \\
\hline $\mathrm{r}^{2}$ (relationship x location) $=0.34$ &
\end{tabular}

Table 3: Main neighbourhood activities (personal perspectives)

\begin{tabular}{|l|c|}
\hline Activities \\
\hline Sport and recreation & 63 \\
\hline Religious & 55 \\
\hline Shopping & 43 \\
\hline Social and community & 35 \\
\hline Other & 15 \\
\hline \multicolumn{2}{|c|}{ (Relative scale) } \\
\hline
\end{tabular}

Consensus: Woldoff (2002) view problem-solving and control mechanisms as crucial parts of neighbourhood based community interaction. But, because of the complexity of expressing and measuring these variables neighbourhood consensus on a number of issues is implemented in this study as indicator of conformity. Table 4 indicates a high level of consensus on the racial profile of the neighbourhood and declining levels of consensus on the predominant language, class status and homogeneity of the neighbourhood. There is also no clear consensus on the issue of racial integration in the neighbourhoods of Pretoria. Areas of particular ambivalence in opinion are also indicated in the table. From the above findings the incidence of confusion of identity is evident in contemporary South African urban local areas. For example, the issue of race in the historical black areas is often confu-sed with tribal divisions based on indigenous languages. Contradictory perceptions on racial integration are to be seen in established, middle-class white suburbs experiencing some level of racial desegregation. Whether the low level of consensus on the homogeneity of the populace is an early outcome of the strategy of race and class integration, the result of spontaneous late-modern socio-spatial urban diversification or simply social confusion is not too clear.

Table 4: Neighbourhood consensus

\begin{tabular}{|l|l|}
\hline On language & $68.2 \%$ \\
\hline $\begin{array}{l}\text { Ambivalence in townships, inner city areas of transformation, suburbs } \\
\text { impacted by gentrification and racial desegregation }\end{array}$ \\
\hline On race & $81.8 \%$ \\
\hline Ambivalence in black and inner city areas \\
\hline On class status & $61.0 \%$ \\
\hline
\end{tabular}




\begin{tabular}{|l|l|}
\hline Ambivalence in townships and high income areas \\
\hline On homogeneity of the populace & $43.5 \%$ \\
\hline Ambivalence in inner city areas, suburbs in transformation and townships \\
\hline On racial integration & $44.2 \%$ \\
\hline Ambivalence in all areas - response not linked to level of desegregation \\
\hline
\end{tabular}

\section{Spatiality}

Spatiality in the neighbourhood context manifests through spatio-temporal operations and territorial definitions.

Spatial operations: One of the main functions of a neighbourhood is to provide in routine daily services (Schnell et al., 2002). From indications, shopping and religious activities emerged as the main local area activities for families as a whole in Pretoria (Table 5). If these acknowledged family activities are compared and combined with self-indicated personal local area activities it follows that South African urban neighbourhoods provide a much wider range of functions than mere shopping facilities. The diversity of activities should, nevertheless, be treated with care though. It is not so much a reflection of traditional old South African neighbourhood values but is more the result of comprehensive socio-economic driven decentralisation processes of nearly all public-orientated functions and services away from the social and physical disorder of the traditional urban heartlands in the inner-city.

Territorial definition: Territorial definition is indicative of a sense of place (Talen, 1999; Schnell et al., 2002) and of territorial images. While this author agrees with Schnell et al. (2002) that spatial familiarity does not co-inside with perceived neighbourhoods I am even more cautious, as Davies and Herbert (1993) are, to link the ability to construct neighbourhood boundaries as cohesive polygons with a sense of neighbourhood. Neighbourhoods are difficult to define, and, as Parkes et al. (2002) suggest, attempts to be prescriptive may prevent respondents from using the concepts of neighbourhood (delineation) that are most relevant to them. Therefore, the way in which individuals delineate perceived neighbourhoods is of much more importance to sense of neighbourhood than the ability to construct cohesively linked boundaries.

Table 5: Family activities in the local area

\begin{tabular}{|l|c|}
\hline Activities \\
\hline Shopping & 148 \\
\hline Religious & 113 \\
\hline Recreation & 63 \\
\hline Sport & 57 \\
\hline Social & 55 \\
\hline Schooling & 43 \\
\hline Cultural & 19 \\
\hline Political & 8 \\
\hline \multicolumn{2}{|c|}{ (Relative scale) } \\
\hline \multicolumn{2}{|c|}{}
\end{tabular}


In this case only $12.3 \%$ of the respondents made no attempt to delineate their respective neighbourhoods while one respondent maintained that "... neighbourhoods do not have boundaries." Hence, $87.0 \%$ verbally constructed some form of boundary for their neighbourhood. In doing so, the average person used at least two entities to describe the neighbourhood's boundaries.

Based on the knowledge that a neighbourhood is an entity that seldom represents officially defined space, is sometimes physically limited, but mostly persists in the minds of people (Garrioch, 2001), particular attention is drawn towards the entities used to describe neighbourhood boundaries. Table 6 (left) shows that 'roads and railways' are by far the most popular entities to describe neighbourhoods, probably because these entities are definitive physical barriers easily perceived as boundaries. 'Nodes' represent the next most popular boundary entity followed by 'bordering areas' and 'natural entities'. In terms of boundary manifestations, Table 6 (right), only $19 \%$ is constructed, cohesive, polygon-type boundaries. The majority described neighbourhood boundaries as arcs $(67 \%)$ and single point descriptions $(20 \%)$. A fairly large proportion of people also viewed their neighbour-hoods as areas in between two entities, and described them as corridors.

Table 6: Neighbourhood boundaries: entities and manifestations

\begin{tabular}{|c|c|c|c|}
\hline \multicolumn{2}{|l|}{ Entities per person } & \multicolumn{2}{|c|}{ Manifestations (relative scale) } \\
\hline Road and rail & 1.18 & Arcs & 67 \\
\hline Nodes & 0.37 & Single point descriptions & 20 \\
\hline Bordering areas & 0.27 & Polygons & 19 \\
\hline Natural entities & 0.22 & Corridors & 18 \\
\hline Personal space & 0.16 & Unspecified polygons & 10 \\
\hline Surrounding areas & 0.16 & No-boundary argument & 1 \\
\hline & & No response & 19 \\
\hline
\end{tabular}

Hence, boundary delineations are an extension of personality rather than ability and great care should be taken in drawing conclusions on the basis of boundary delineations with regard to sense of neighbourhood and even sense of place.

\section{CONCLUSION}

A number of specific conclusions can be drawn.

- Community consensus and relations in both black and white societies are weak in Pretoria, a developing city of the South amidst rapid social transformation.

- Local areas play only a relatively important role in the lives of people although strong perceptions of neighbourhood are being held.

- Neighbourhood symbols and evaluations represent area specific balances between social and environmental qualities, on the one hand, and social and physical disorder on the other hand. 
- The majority of respondents are able to delineate their neighbourhoods using a number of entities; for this majority the neighbourhood is a personal definition of a local area with porous boundaries.

Two general comments should be added.

- The study of sense of neighbourhood is not about the relevance of neighbourhood but about its relative importance in point and time and about personal, social and spatial manifestations of neighbourhood.

- Can one conclude that the main function of the neighbourhood in a late-modern society in transition is to exist in the minds of people as a reminder of community when the level of social confusion is high?

\section{References}

Ainsworth, J.W., 2002. Why does it take a village? The mediation of neighbourhood effects on educational achievement. Social Forces, 81, p. 117-152.

Briggs, X de Souza., 2001. Ties that Bind, Bridge, and Constrain: Social Capital and Segregation in the American Metropolis. Paper prepared for the International Seminar on Segregation and the City, 25-28 July, Lincoln Institute of Land Policy, Cambridge, MA, U.S.A.

Calthorpe, P., 1993. The next American metropolis: ecology, community, and the America dream. New York, Princeton Architectural Press.

Davies, W. and Herbert, D., 1993. Communities within Cities. London, Printer.

Durkheim, E., 1933. The Division of Labour in Society, (translated). New York, Free Press.

Ellen, I.G. and Turner, M.A., 1997. Does neighbourhood matter? Assessing recent evidence. Housing Policy Debate, 8, p. 833-866.

Fischer, C.S., 1982. To Dwell Among Friends: Personal Networks in Town and City. Chicago, Chicago University Press.

Fischer, C.S., 1984. The Urban Experience. New York, Harcourt, Brace, Jovanovich.

Gans, H.J., 1962. The Urban Villagers: Group and Class in the Life of Italian-Americans. New York, Free Press.

Garrioch, D., 2001. Sacred neighborhoods and secular neighborhoods: Milan and Paris in the Eighteenth century. Journal of Urban History, 27, p. 405-419.

Geis, K.J. and Ross, C.E., 1998. A new look at urban alienation: the effect of neighbourhood disorder on perceived powerlessness. Social Psychological Quarterly, 61, p. 232-246.

Gibbons, S., 2003. Paying for good neighbours: estimating the value of an implied educated community. Urban Studies, 40, p. 809-833.

Goering, J.M., 1978. Neighborhood tipping and racial transition: a review of social science evidence. Journal of the American Planning Association, 44, p. 68-78.

Herbert, D. and Thomas, C.J., 1982. Urban Geography: A First Approach. New York, John Wiley \& Sons.

Hull, R.B. 1992, Image, congruity, place attachment and community design. The Journal of Architectural and Planning Research, 9, p. 181-192. 
Kallus, R. and Law-Yone, H., 2000. What is a Neighbourhood? The Structure and Function of an Idea. UK, Pion.

Kasarda, J.D. and Janowitz, M., 1974. Community attachment in mass society, American Sociological Review, 39, p. 328-339.

Keller, S. 1968. The Urban Neighbourhood. New York, Random House.

Lyon, L., 1989. The Community in Urban Society, Prospect Heights, IL, Waveland Press.

May, R., 1983. The Discovery of being. New York, Basic Books.

McMillan, D.W., and Chavis, D.M., 1986. Sense of community: a definition and theory. Journal of Community Psychology, 14, p. 6-23.

Michelson, W.H., 1970. Man and His Urban Environment: A Sociological Approach. Reading, MA, Addisson-Wesley.

Moeser, J.V., 2001. The old neighbourhood in art and word. Journal of Urban History, 27, p. 178-192.

Muller, P.O., 1981, Contemporary Suburban America. Englewood Cliffs NJ, Prentice-Hall.

Ostendorf, W. (et al.), Musterd, S., and de Vos, S., 2002. Impact of the residential environment on social mobility in The Netherlands: differences in vulnerability. Paper presented at the Perspective on Urban Spheres Conference, Pretoria, University of Pretoria.

Park, R.E. (et al.), Burgess, E.W. and McKenzie, R.D. (eds)., 1925. The City. Chicago, University of Chicago Press.

Parkes, A. (et al.), Kearns, A., and Atkinson, R., 2002. What makes people dissatisfied with their neighbourhoods? Urban Studies, 39, p. 2413-2438.

Porteous, J.D., 1977. Environment and Behaviour: Planning and Everyday Urban Life, Colombia (Canada), University of Victoria.

Prinsloo, E., 1998, Social change in South Africa: opportunity or crisis?. Society in Transition, 29, p. 13-21.

Rankin, B.H., and Quane, J.M., 2000. Neighbourhood poverty and the social isolation of inner-city African American families. Social Forces, 79, p. 139-164.

Relph, E.C., 1976. Place and Placelessness, London, Pion.

Schnell, I. (et al.), Benjamini, Y., and Pash, D., 2002. Neighbourhoods as territorial units: the case of Tel-Aviv-Jaffa. Paper presented at the Perspective on Urban Spheres Conference, Pretoria, University of Pretoria.

Sies, M.C. 2001. North American suburbs, 1880-1950: cultural and social reconsiderations. Journal of Urban History, 27, p. 313-346.

South Africa, 1995. Urban Development Strategy of the Government of National Unity. Cape Town, Government Printer.

South Africa, 1998. The White Paper on Local Government. Cape Town, Government Printer.

South, S.J., and Crowder, K.D., 2000. The declining significance of neighbourhoods? Marital traditions in community context. Social Forces, 78, p. 1067-1099.

Suarez, R., 2000. The Old Neighbourhood: What We Lost in the Great Suburban Migration: 1966-1999. New York, Free Press.

Talen, E., 1999. Sense of community and neighbourhood form: an assessment of the social doctrine of new urbanism. Urban Studies, 36, p. 1361-1379. 
Tönnies, F., 1963. Community and Society, translated. New York, Harper and Row. Uitermark, J., 2003. 'Social mixing' and the management of disadvantaged neighbourhoods: the Dutch policy of urban restructuring revisited. Urban Studies, 40, p. 531-549.

Walker, G., 1989. Neighbourhoods: Theoretical Interpretations. York, York University.

Webber, M.M., 1963. Order in diversity: community without propinquity, In Wingo, L., (ed.) Cities and Space. Baltimore, John Hopkins Press, p. 23-56.

Wellman, B.,1979. The community question. American Journal of Sociology, 84, p. 12011231.

Wellman, B and Leighton, B., 1979. Networks, neighbours and communities. Urban Affairs Quarterly, 14, p. 363-390.

Wilson, W., 1987. The Truly Disadvantaged: The Inner City, the Underclass, and Public Policy. Chicago, University of Chicago Press.

Wirth, L., 1938. Urbanism as a way of life. American Journal of Sociology, 44, p.1-24.

Woldoff, R.A., 2002, The effects of local stressors on neighbourhood attachment. Social Forces, 81, p. 87-116.

Zimmerman, C.C., 1938. The Changing Community. New York, Harper and Row. 